\title{
The use of Zeta Potential Measurement as a Control Tool of Surface Water Coagulation
}

\author{
Dominik Mroczko ${ }^{1,2}$, Izabela Zimoch ${ }^{1 *}$ \\ 1 Silesian University of Technology, Faculty of Energy and Environmental Engineering, Institute of Water and \\ Wastewater Engineering, ul. Konarskiego 18, 44-100 Gliwice, Poland \\ 2 P.U.T. DEMPOL-ECO, ul. Składowa 9, 45-125 Opole, Poland \\ * Corresponding author's e-mail: izabela.zimoch@polsl.pl
}

\begin{abstract}
The implementation or optimization of the coagulation process requires prior preliminary tests. Standard Jar-Test method is time-consuming, inaccurate and may not work well, especially for the waters characterized by high variability of quality parameters. Zeta Potential Isoelectric Point (IEP) analysis may give fast and precise data on the coagulant type and dose required for maintaining an efficient coagulation process. The research objects included the surface waters taken directly from the Mała Panew and Odra rivers. The zeta potential and set coagulant dose dependence was measured for each sample. Four aluminum-based coagulants with different characteristics were used in this research: aluminum sulfate (Alum), polyaluminum chloride (PAC), dialuminum chloride pantahydroxide (PACl), polyaluminum chloride hydroxide sulfate (PACS). Charge neutralization effectiveness, by means of Zeta Potential IEP analysis, was the basis for the choice of the most effective coagulant doses. The coagulation process efficacy was based on the parameters of the treated water ( $\mathrm{pH}$, turbidity, color, alkalinity), reduction of organic matter (Abs254, Total Organic Carbon (TOC), Dissolved Organic Carbon (DOC)) and residual aluminum contamination. The Zeta Potential utility evaluation was based on the DOC reduction.
\end{abstract}

Keywords: zeta potential, isoelectric point, coagulation, aluminum, coagulants, surface water

\section{INTRODUCTION}

Seasonal changes in the quality parameters of waters (especially surface waters) [Chittor, Molson and Schirmer, 2015, Tsirkunov et al., 1992, Sappa et al., 2015], including temperature, turbidity, $\mathrm{pH}$, natural organic matter and inorganic contaminants often forces the treatment plants operators to change the conditions of the coagulation process in order to meet the water quality requirements [Mroczko and Zimoch, 2018]. In critical situations, especially at the turn of the seasons, the coagulant dose adjustment may not be sufficient and it justifies the coagulant type change [Cochran, 2010]. Usually, coagulant dose correction is not in time being a reaction to the already deteriorated quality of the treated water. The most popular method of determining the coagulant dose is a classic Jar-Test. This method, however, has its limitations: it is time-consuming, does not represent the essence of the problem and often ends as an blind shot [Edney, 2005].

The coagulation process is mainly based on double layer repulsive potential reduction by neutralization of surface charge of pollutants [Hunter, 1988, Lopez-Maldonado, 2014, Matilainen, Vepsalainen and Sillanpaa, 2010]. Zeta potential (ZP) is the parameter that provides the information about the charge neutralization status. Most naturally occurring waters have the negative-charged colloidal contaminants due to polar matrix ions adsorption on its surface, making the $\mathrm{ZP}$ value also negative [Salopek, Krasic and Filipovic, 1992]. Adding highly positively charged coagulants (i.e. aluminum- or iron based salts) neutralizes the surface charge, shifting ZP towards positive values. Zero point, called isoelectric point (IP), where $\mathrm{ZP}=0 \mathrm{mV}$, means the 
balance of positive and negative charge components, where the colloidal suspension is maximally destabilized and coagulation process is most effective [Hunter, 1988, Ordaz-Diaz, 2017]. However some studies [Han et al., 2011, Morfesis et al., 2009, Sharp et al., 2005, Tang, Xiao and Wang, 2015] proves that the operational coagulation conditions may be in some wider ranges of the $\mathrm{ZP}$ value.

With this work, the authors wanted to make a contribution to the existing data about ZP measurement value, having in mind that the current knowledge is based on case studies. In the presented study, we have shown the results of the zeta potential measurement evaluation as a coagulation process control tool in the context of Dissolved Organic Carbon (DOC) removal. The coagulant type and dose prediction by the ZP measurement was analyzed. The four aluminum based coagulant types effectiveness was also studied. The coagulant doses were determined by means of the IP analysis. For this purpose, aluminum doses in dependence of the ZP value, $\zeta=\mathrm{f}(\mathrm{mgAl} \cdot 1-1)$, were defined. The main aim of the presented research was to check ZP measurement utility by finding unequivocal system response. In the presented case, the authors have been looking for the DOC reduction slowdown. On the basis of the IP analysis results, 5 coagulants doses were chosen: IP dose, IP $+10 \%$, IP $+20 \%$, IP- $10 \%$, IP-20\%. Additional quality parameters, measured in IP dose only, such as $\mathrm{pH}$, turbidity, color, alkalinity, Abs254, Total Organic Carbon (TOC) and residual aluminum were measured for ZP precision and coagulation effectiveness evaluation.

\section{MATERIALS AND METHODS}

\section{Materials}

The raw waters used in this study were the surface waters from the Mała Panew (MaPa) and Odra rivers collected in Czarnowąsy and Brzeźce, respectively. The characteristics of waters are shown in Table 3.

Four types of aluminum-based coagulants were used. The first was aluminum sulfate (Alum) ( $0.16 \mathrm{~mol} \mathrm{l}^{-1}$ solution), representing the conventional aluminum coagulants. Another coagulant used was polyaluminum chloride (PAC), as a representative of the group of low-basic coagulants. The last two coagulants used in this study were: dialuminum chloride pantahydroxide (PACl), and polyaluminum chloride hydroxide sulfate (PACS) representing a group of high-basic and pre-hydrolyzed coagulants.

The chosen coagulants were selected due to their different coagulation mechanisms. Surveys [Chen, 2007, Tang, Xiao and Wang, 2015, Zhang et al., 2004] suggest that the basicity of coagulants has an impact on the hydrolysis products during the coagulation process. The use of lowbasic coagulants such as Alum and PAC promotes the formation of mainly low-charged $\mathrm{Al}(\mathrm{OH})_{3}$ and monomeric structures, while increased basicity results in the creation of mid and high polymeric species, including strongly desirable, high-charged Al13 clusters [Hu et al., 2006]. The characteristics of coagulants used in this study are shown in Table 1.

\section{Analytical method}

Characterization of coagulants was carried out according to the PN-EN 1302:2001 standard.

The ZP analysis was conducted with Malvern Zetasizer Nano which uses the electrophoretic light scattering measuring technique. The $\mathrm{ZP}$ measurement was conducted with simultaneous coagulant dosing.

The coagulation processes were performed using the jar test method with consecutive: fastmixing phase (100 rpm, 1 minute), slow-mixing phase (40 rpm, 15 minutes) and sedimentation (60 minutes).

DOC and TOC were measured by means of Analytikjena Multi N/C 3100. The Al concentration was analyzed with the GF-AAS method, on the Analytikjena contrAA 700 spectrometer. Other parameters were performed according to Standard Procedures.

\section{RESULTS}

\section{The Zeta Potential analysis}

The ZP analysis were performed to observe charge neutralization potential of different coagulants as well as to determine the IPs. Due to various $\mathrm{Al} 3+$ concentrations in the coagulants tested, dosage has been standardized as the amount of aluminum added to the sample during process. The ZP measurement results are shown in Figure 1 and 2 . In both cases the $\mathrm{ZP}$ value rose 
Table 1. Characteristics of the used coagulants

\begin{tabular}{|l|c|c|c|c|}
\hline \multicolumn{1}{|c|}{ Parameter } & PACl & PACS & PAC & Alum $^{1)}$ \\
\hline $\mathrm{Al}^{3+}, \%$ mas. & 11.55 & 9.10 & 8.46 & 9.10 \\
\hline $\mathrm{Cl}^{-} \%$ mas. & 6.31 & 6.08 & 22.6 & - \\
\hline $\mathrm{pH}$ & 4.24 & 4.03 & 1.12 & 3.21 \\
\hline Basicity, $\%$ & 86.15 & 83.07 & 32.32 & 0 \\
\hline $\mathrm{OH} / \mathrm{Al}$ & 2.58 & 2.49 & 0.97 & - \\
\hline${ }^{1)} \mathrm{as} \mathrm{Al}_{2}\left(\mathrm{SO}_{4}\right)_{3} \cdot 16 \mathrm{H}_{2} \mathrm{O}$ & \multicolumn{3}{|l}{} \\
\hline
\end{tabular}

rapidly and achieved IP the fastest with PACl. On the other hand, Alum caused relatively slow charge neutralization, being the least effective in reaching IP in both cases. In the case of the Odra river, the $\mathrm{ZP}$ value crossed zero point almost 4 times faster with $\mathrm{PACl}$ than with Alum (3.44 to $13.4 \mathrm{mgAl} \cdot 1-1)$. For Mała Panew as well as for Odra, the order of reaching IP was: PACl, PACS, PAC, Alum, respectively; however, for Odra, the difference between PACS and PAC was insignificant (5.19 and $5.33 \mathrm{mgAl} \cdot 1-1)$. Full IP dose demand analysis was shown in Table 2.

\section{Coagulation IP dose effectiveness}

Jar test coagulations were performed to evaluate precision and effectiveness in the IP dose of coagulants. In both cases, for all coagulants used, the reduction values reached similar values within the reduced parameters. For example, in the case of $\mathrm{MaPa}$ the $\mathrm{DOC}$ reduction was in a narrow range of 36.6 to $41.1 \%$, and for Odra - from 29.6 to $32.7 \%$. Analogical situation repeated for color, TOC, turbidity and absorbance, which may confirm that the ZP IP dose, despite coagulants differences, actually is relatively precise.

Additionally, in the case of low-basic coagulants, some negative phenomena appeared, such as significant acidification (in the case of $\mathrm{MaPa} \mathrm{pH}$ dropped by 1.47 for Alum, and by 1.04 for PAC, in the case of Odra respectively by 1.60 and 0.60 ; alkalinity decreased by 0.94 and $0.55 \mathrm{mval}^{\cdot \mathrm{l}^{-1}}$ in the case of $\mathrm{MaPa}$, and by 0.67 and $0.33 \mathrm{mval} \cdot \mathrm{l}^{-1}$ for Odra), or residual aluminum recontamination (especially Alum: Al concentration increased by $620 \mu \mathrm{g} \cdot \mathrm{l}^{-1}$ in the case of $\mathrm{MaPa}$, and by $636 \mu \mathrm{g} \cdot \mathrm{l}^{-1}$

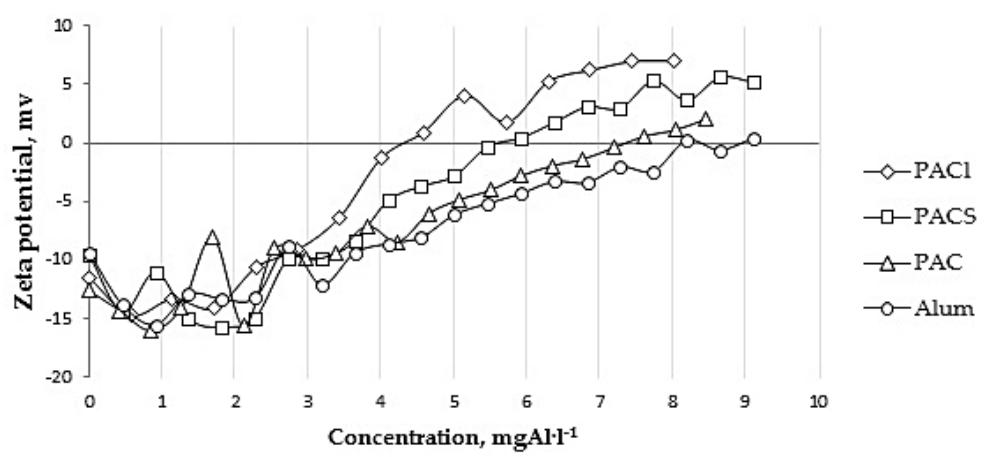

Fig. 1. Zeta potential in dependence of the $\mathrm{Al}$ dose: $\mathrm{MaPa}$

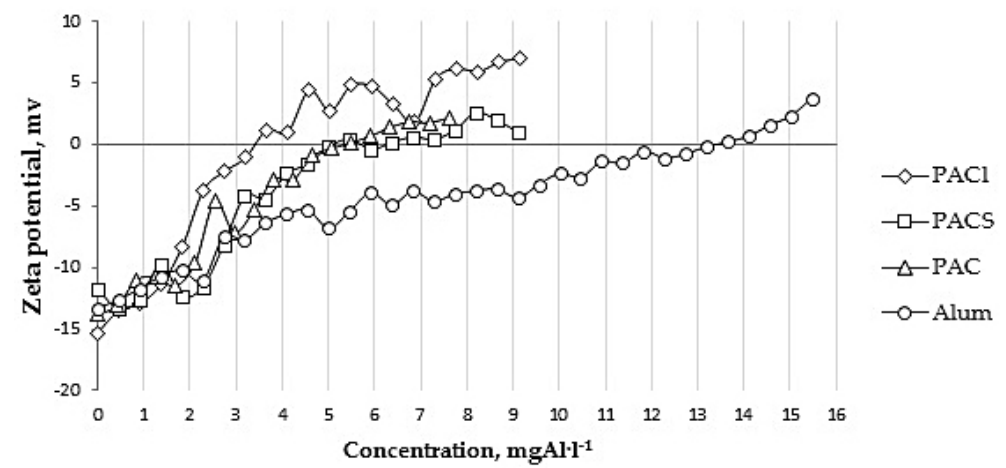

Fig. 2. Zeta potential in dependence of the Al dose: Odra 
Table 2. IP point analysis

\begin{tabular}{|c|c|c|c|c|c|}
\hline \multicolumn{2}{|c|}{ IP dose demand } & PACl & PACS & PAC & Alum $^{1)}$ \\
\hline \multirow{2}{*}{$\mathrm{MaPa}$} & $\mathrm{mg} \cdot \mathrm{l}^{-1}$ & 38 & 62 & 87 & 98 \\
\cline { 2 - 6 } & $\mathrm{mgAl} \cdot \mathrm{l}^{-1}$ & 4.39 & 5.64 & 7.36 & 8.92 \\
\hline \multirow{2}{*}{ Odra } & $\mathrm{mg} \cdot \mathrm{l}^{-1}$ & 30 & 57 & 63 & 147 \\
\cline { 2 - 6 } & $\mathrm{mgAl} \cdot \mathrm{l}^{-1}$ & 3.44 & 5.19 & 5.33 & 13.4 \\
\hline \multicolumn{2}{|c|}{${ }^{1)} \mathrm{as} \mathrm{Al}_{2}\left(\mathrm{SO}_{4}\right)_{3} \cdot 16 \mathrm{H}_{2} \mathrm{O}$} \\
\hline
\end{tabular}

Table 3. Raw and IP-dose coagulated waters characteristics

\begin{tabular}{|c|c|c|c|c|c|c|c|c|c|c|}
\hline \multirow{3}{*}{ Parameter } & \multicolumn{10}{|c|}{ Study object } \\
\hline & \multicolumn{5}{|c|}{$\mathrm{MaPa}$} & \multicolumn{5}{|c|}{ Odra } \\
\hline & Raw & $\mathrm{PACl}$ & PACS & PAC & Alum & Raw & $\mathrm{PACl}$ & PACS & PAC & Alum \\
\hline $\mathrm{pH}$ & 7.95 & 7.81 & 7.75 & 6.91 & 6.48 & 6.84 & 6.81 & 6.79 & 6.24 & 5.24 \\
\hline Alkalinity, mval $\left.\right|^{-1}$ & 1.95 & 1.87 & 1.84 & 1.40 & 1.01 & 1.60 & 1.55 & 1.54 & 1.27 & 0.93 \\
\hline Color, mgPt.l-1 & 53 & 6 & 5 & 5 & 5 & 34 & 4 & 4 & 4 & 4 \\
\hline Turbidity, NTU & 10.9 & 0.77 & 0.77 & 0.84 & 1.78 & 12.6 & 1.54 & 0.98 & 1.24 & 2.64 \\
\hline $\mathrm{Abs}_{254}$ & 0.995 & 0.316 & 0.330 & 0.323 & 0.317 & 0.795 & 0.310 & 0.297 & 0.310 & 0.343 \\
\hline TOC, $\mathrm{mg} \mathrm{l}^{-1}$ & 6.48 & 3.73 & 3.94 & 4.00 & 3.85 & 3.93 & 2.01 & 2.12 & 2.05 & 2.21 \\
\hline $\mathrm{DOC}, \mathrm{mg}^{-1}$ & 6.28 & 3.70 & 3.82 & 3.98 & 3.73 & 3.86 & 2.62 & 2.69 & 2.60 & 2.72 \\
\hline $\mathrm{Al}, \mu \mathrm{g} \cdot \mathrm{l}^{-1}$ & 92.72 & 97.70 & 23.51 & 206.2 & 712.3 & 264.3 & 254.2 & 281.5 & 320.5 & 900.6 \\
\hline
\end{tabular}

Table 4. Complete coagulants doses used in Jar-Test

\begin{tabular}{|c|c|c|c|c|c|c|c|c|}
\hline \multirow{3}{*}{ Parameter } & \multicolumn{8}{|c|}{ Study object } \\
\hline & \multicolumn{4}{|c|}{$\mathrm{MaPa}$} & \multicolumn{4}{|c|}{ Odra } \\
\hline & $\begin{array}{c}\mathrm{PACl} \\
{\left[\mathrm{mg}^{-1} \mathrm{l}^{-1}\right]}\end{array}$ & $\begin{array}{l}\text { PACS } \\
{\left[\mathrm{mg}^{-1} \mathrm{l}^{-1}\right]}\end{array}$ & $\begin{array}{c}\mathrm{PAC} \\
{\left[\mathrm{mg} \cdot \mathrm{I}^{-1}\right]}\end{array}$ & $\begin{array}{l}\text { Alum }^{1)} \\
{\left[\mathrm{mg}^{-1} \mathrm{I}^{-1}\right]}\end{array}$ & $\begin{array}{c}\mathrm{PACl} \\
{\left[\mathrm{mg}^{-1} \mathrm{l}^{-1}\right]}\end{array}$ & $\begin{array}{l}\text { PACS } \\
{\left[\mathrm{mg}^{-1} \mathrm{l}^{-1}\right]}\end{array}$ & $\begin{array}{c}\text { PAC } \\
{\left[\mathrm{mg} \cdot \mathrm{I}^{-1}\right]}\end{array}$ & $\begin{array}{l}\text { Alum }^{11} \\
{\left[\mathrm{mg}^{-1} \mathrm{l}^{-1}\right]}\end{array}$ \\
\hline IP-20\% & 30.4 & 49.6 & 69.6 & 78.4 & 24.0 & 45.6 & 50.4 & 117.6 \\
\hline IP-10\% & 34.2 & 55.8 & 78.3 & 88.2 & 27.0 & 51.3 & 56.7 & 132.3 \\
\hline IP & 38.0 & 62.0 & 87.0 & 98.0 & 30.0 & 57.0 & 63.0 & 147.0 \\
\hline $\mathrm{IP}+10 \%$ & 41.8 & 68.2 & 95.7 & 107.8 & 33.0 & 62.7 & 69.3 & 161.7 \\
\hline $\mathrm{IP}+20 \%$ & 45.6 & 74.4 & 104.4 & 117.6 & 36.0 & 68.4 & 75.6 & 176.4 \\
\hline \multicolumn{9}{|c|}{ 1) as $\mathrm{Al}_{2}\left(\mathrm{SO}_{4}\right)_{3} \cdot 16 \mathrm{H}_{2} \mathrm{O}$} \\
\hline
\end{tabular}

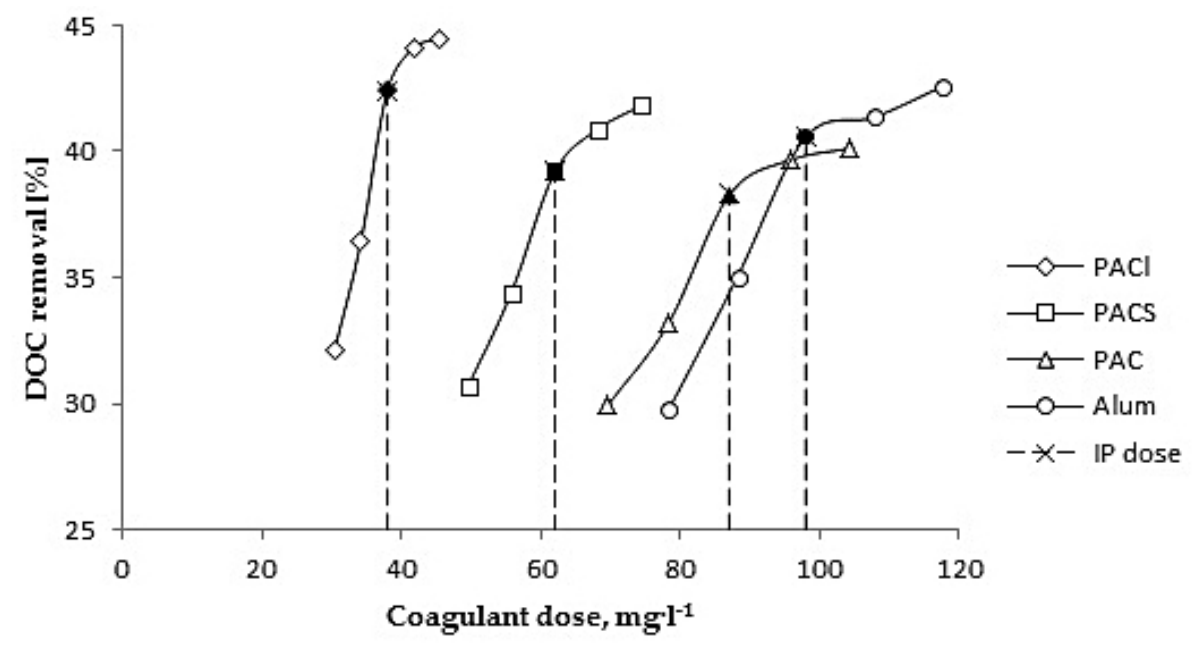

Fig. 3. DOC reduction in 5 coagulation doses: $\mathrm{MaPa}$

Filled markers are for DOC removal decrease point indication 
for Odra). Complete IP dose coagulation results are shown in Table 3.

\section{Zeta potential and DOC reduction}

Additional coagulations at doses above and below (10 and 20 percent each; complete coagulants doses are in Table 4) IP were made to evaluate the DOC reduction kinetics. In the case of $\mathrm{MaPa}$, the DOC reduction was the most effective with the highest coagulant dose, which is not surprising at all. More important was the fact that after reaching IP, the organic matter reduction distinctly decreased regardless of the coagulant used (Fig. 3).

In the case of the Odra river, the DOC reduction started decreasing in negative or positive ZP values. PACl and PACS (both high-basic) organics removal effectiveness dropped in the ZP values about $-1,5 \mathrm{mV}$, while low-basic coagulants at about $1 \mathrm{mV}$ (PAC) and $1.5 \mathrm{mV}$ (Alum) (Fig. 4). Still, operating nearby or just at IP provided optimal coagulation conditions, in terms of the organic matter removal. Complete DOC results are in Table 5.

\section{CONCLUSIONS}

The presented research confirms potential utility of Zeta Potential measurement as a coagulation control tool in terms of organic matter removal. In the tested cases, ZP turned out to be promising alternative for a standard Jar-Test, as relatively quick and precise coagulant type and dose prediction real-time method. The Zeta Potential measurement, giving insight into coagulation process essence in real time, seems to be resistant to a rapid water quality change. However, the implementation of $\mathrm{ZP}$ as a control instrument definitely should be preceded by preliminary tests, as the optimal coagulation point may be slightly different than theoretical $0 \mathrm{mV}$ point.

In the considered cases, high-basic coagulants appeared to be more efficient in charge neutralization, thus reached Isoelectric Point at lower Al doses compared to low-basic ones. This is due to its high content of desirable, high-charged Al species. Additionally, the use of high-basic coagulants, in comparison to PAC and Alum, does not negatively affect the treated water.

Table 5. Jar-Test DOC removal results

\begin{tabular}{|c|c|c|c|c|c|c|c|c|c|}
\hline \multirow{3}{*}{\multicolumn{2}{|c|}{ Parameter }} & \multicolumn{8}{|c|}{ Study object } \\
\hline & & \multicolumn{4}{|c|}{$\mathrm{MaPa}$} & \multicolumn{4}{|c|}{ Odra } \\
\hline & & $\mathrm{PACl}$ & PACS & PAC & Alum & $\mathrm{PACl}$ & PACS & PAC & Alum \\
\hline \multirow{5}{*}{$\begin{array}{c}\mathrm{DOC} \\
{\left[\mathrm{mg} \cdot \mathrm{l}^{-1}\right]}\end{array}$} & IP-20\% & 4.40 & 4.49 & 4.54 & 4.55 & 3.12 & 3.03 & 3.13 & 3.28 \\
\hline & IP-10\% & 4.12 & 4.25 & 4.33 & 4.21 & 2.68 & 2.71 & 2.78 & 2.96 \\
\hline & IP & 3.73 & 3.94 & 4.00 & 3.85 & 2.62 & 2.70 & 2.60 & 2.72 \\
\hline & $\mathrm{IP}+10 \%$ & 3.62 & 3.83 & 3.91 & 3.80 & 2.57 & 2.65 & 2.47 & 2.55 \\
\hline & IP+20\% & 3.60 & 3.77 & 3.88 & 3.72 & 2.56 & 2.65 & 2.44 & 2.53 \\
\hline
\end{tabular}

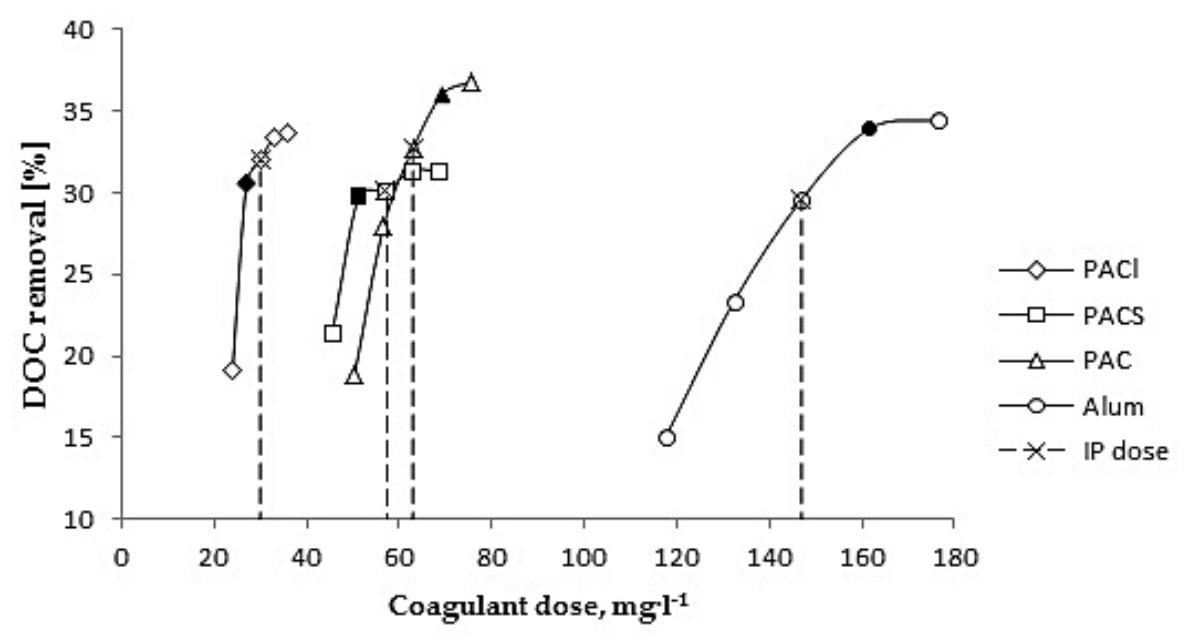

Fig. 4. DOC reduction in 5 coagulation doses: Odra

Filled markers are for DOC removal decrease point indication 


\section{Acknowledgments}

This study was supported by the Ministry of Science and Higher Education within grant designated for realization of the project "Implementation Ph. D" and within BKM/ RIE-4 / 2018 grant.

\section{REFERENCES}

1. Chen Z., Luan Z., Fan J., Zhang Z., Peng X., Fan B. 2007. Effect of thermal treatment on the formation and transformation of Keggin A113 and Al30 species in hydrolytic polymeric aluminum solutions. Colloids and Surfaces a Physicochemical Engineering Aspects, 292 (2-3), 110-118.

2. Chittoor V.V., Molson J. Schirmer M. 2015. Does river restoration affect diurnal and seasonal changes to surface water quality? A study along the Thur River, Switzerland. Science of the Total Environment, 532, 91-102.

3. Cochran J., Barron P., Nabors A., Cox W. 2010. Using a mobile pilot plant to evaluate need and protocol for a previously failed coagulant changeover. Proc. World Environmental and Water Resources Congress 2010: Challenges of Change, 3604-3611.

4. Edney D. 2005. Introduction to the theory of the streaming current meter. Application Note, Accurate Measurements NZ Ltd.

5. Han Y., Jiang Z., Zhou X., Peng D. 2011. The effect of dissolved organic matter on Zeta potential during the coagulation process. 2011 International Conference on Computer Distributed Control and Intelligent Environmental Monitoring.

6. Hunter R.J. 1988. Zeta Potential in Colloid Science. Principles and Applications. Academic Press.

7. Hu C., Liu H., Qu J., Wang D., Ru J. 2006. Coagulation Behavior of Aluminum Salts in Eutrophic Water: Significance of A113 Species and pH Control. Environmental Science \& Technology, 40 (1), 325-331.

8. Lopez-Maldonado E.A, Oropeza-Guzman M.T, Jurado-Baizaval J.L., Ochoa-Teran A. 2014. Coagulation-flocculation mechanism in wastewater treatment plants through zeta potential measurements. Journal of Hazardous Materials, 279, 1-10.

9. Matilainen A., Vepsalainen M., Sillanpaa M. 2010. Natural organic matter removal by coagulation during drinking water treatment: A review. Advances in Colloid and Interface Science, 159 (2), 189-197.
10. Morfesis A., Jacobson A.M., Frollini R., Helgeson M., Billica J., Gertig K.R. 2009. Role of Zeta Potential in the Optimization of Water Treatment Facility Operations. Industrial \& Engineering Chemistry Research, 48, 2305-2308

11. Mroczko D., Zimoch I. 2018. Coagulation of pollutions occurring in surface waters during time of dynamic water flow. Ecological Engineering, 19 (2), 15-22 (in Polish).

12. Ordaz-Diaz L.A., Valle-Cervantes S., RodriguesRosales J., Bailon-Salas A.M., Madrid-Del Palacio M., Torres-Fraga K., De la Pena-Arellano L.A. 2017. Zeta potential as a tool to evaluate the optimum performance of a coagulation-flocculation process for wastewater internal treatment for recirculation in the pulp and paper process. BioResources, 12 (3), 5953-5969.

13. Salopek B., Krasic D., Filipovic S. 1992. Measurement and application of zeta-potential. Rudarskogeolosko-naftni zbornik, 4, 147-151.

14. Sappa G., Ergul S., Ferranti F., Ngalya Sweya L. Luciani G. 2015. Effects of seasonal change and seawater intrusion on water quality for drinking and irrigation purposes, in coastal aquifers of Dar es Salaam, Tanzania. Journal of Africa Earth Science, 105, 64-84.

15. Sharp E.L., Banks J., Ballica J.A., Gertig K.R., Parsons S.A., Wilson D., Jefferson B. 2005. Application of zeta potential measurements for coagulation control: pilot-plant experiences from UK and US waters with elevated organics. Water Science and Technology: Water Supply, 5 (5), 49-56

16. Sharp E.L., Parsons S.A., Jefferson B. 2004. The effects of changing NOM composition and characteristics on coagulation performance, optimization and control. Water Science and Technology: Water Supply, 4 (4), 95-102

17. Tang H., Xiao F., Wang D. 2015. Speciation, stability, and coagulation mechanisms of hydroxyl aluminum clusters formed by $\mathrm{PACl}$ and alum: A critical review. Advances in Colloid and Interface Science, 226, 78-85

18. Tsirkunov V.V, Nikanorov A.M., Laznik M.M., Dongwei, Z. 1992. Analysis of long-term and seasonal river water quality changes in Latvia. Water Research, 26, 1203-1216.

19. Zhang P., Hahn H.H, Hoffmann E., Zeng G. 2004. Influence of some additives to aluminium species distribution in aluminium coagulants. Chemosphere, 57 (10), 1489-1494. 